\title{
Development a Generic Transaction Processing System Based on Business Process Metadata
}

\author{
Addin Gama Bertaqwa \\ Fakultas Teknik, Universitas Nahdlatul \\ Ulama NTB, Mataram, Nusa Tenggara \\ Barat, Indonesia \\ addingama@gmail.com
}

\author{
G.A. Putri Saptawati \\ Sekolah Teknik Elektro dan Informatika, \\ Institut Teknologi Bandung, Bandung, \\ Jawa Barat, Indonesia \\ putri@informatika.org
}

\author{
Tricya E. Widagdo \\ Sekolah Teknik Elektro dan Informatika, \\ Institut Teknologi Bandung, Bandung, \\ Jawa Barat, Indonesia \\ cia@informatika.org
}

\begin{abstract}
The business process has a major role in organization activities. Various information systems supporting organization business processes, one of them is the transaction processing system that serves to record the daily routine transactions necessary in running a business. In the system implementation, often occur repetitive coding for additions or changes to the business process. Business processes consist of a collection of related activities. To overcome the repetitive coding implementation, relations between activities must be modeled. In this research, business processes mapping to data level using a metadata approach is proposed as a solution to manage any execution services build in the information systems so that developers can focus on business process flows. The data model divide business process into three building blocks: event, task and gateway. The transaction processing system and the executor of the business process have been developed based on designed metadata. The test results concluded that metadata is able to define the business process, and the executor can control the flow of executions of business processes correctly.
\end{abstract}

Keywords: Business process, data model, transaction processing system, executor.

\section{Introduction}

In the implementation of activities within an organization, there are administrative processes that must be done to sustain continuity. The administrative process generally involved the process of recording, file processing and simple bookkeeping. Information technology is advancing faster than technologies for physical processing (Porter \& Millar, 1985). Now the process and information technology are viewed as industrial engineering that can change how an organization works (Davenport \& Short, 1990). Based on the phenomenon a few ideas to use information technology simplified and fasten the administration process of organizations. Organizations can have different types of information systems, one of which is a transaction processing system. Information technology is advancing faster than technologies for physical processing (Porter \& Millar, 1985). Now the process and information technology are viewed as industrial engineering that can change how an organization works (Davenport 
\& Short, 1990). Based on the phenomenon a few ideas to use information technology simplified and fasten the administration process of organizations. Organizations can have different types of information systems, one of which is a transaction processing system. Transaction processing systems (TPS) are the basic business systems that serve the operational level of the organization. A transaction processing system is a computerized system that performs and records the daily routine transactions necessary to the conduct of the business.

Transaction processing systems are typically built to support the needs of very specific business processes. It would be a problem if there are additional or changes in supported business processes that causing repetitive coding activities to implement the business processes. Solutions to that problem have been found by Terahadi and Widagdo (2014). Terahadi and Widagdo (2014) have successfully developed a data model capable of storing information about business processes and create an executor to execute business processes based on user-defined queries. The relation between the activity successfully saved so that business processes can be manually executed correctly.

This research will focus on developing the data model of business processes to store the relationships among the activities to allow the definition of rules for each relationship. A transaction processing system constructed by utilizing the data model as a solution to the problem of repetitive coding during the implementation of business processes into information systems.

\section{Literature}

\section{Transaction Processing System}

Transaction processing systems (TPS) are the basic business systems that serve the operational level of the organization. A transaction processing system is a computerized system that performs and records the daily routine transactions necessary to the conduct of the business (Srinivas \& DBA, 2012). Transaction processing system has the following characteristics (Ghaebi, 2016):

- Input: transaction or event

- Process: adding, updating, sorting and listing.

- Output: detailed reports; lists; summary

- User: operational personnel, supervisor

\section{Metadata}

Metadata is structured information that describes, explains, locates, or otherwise makes it easier to retrieve, use, or manage an information resource. Metadata is often called data about data or information about information (NISO, 2004).

\section{Business Process}

Michael Hammer and James Champy define a business process as a collection of activities that take one or more kinds of input and create an output that is of value to the customer (Hammer \& Champy, 2009). Execution constraints between activities are identified by Davenport, who defines a business process as "a set of logically related tasks performed to achieve a defined business outcome for a particular customer or market.". Davenport also considers the relationship of process activities, including their execution ordering, by defining a business process as "a specific ordering of work activities across time and place, with a beginning, an end, and identified inputs and outputs." $\mathrm{He}$ continues, "business processes have customers (internal or external) and they cross organizational boundaries, i.e., they occur across or between organizational subunits." (Davenport \& Short, 1990).

\section{Business Process Modelling Notation}

Many notations that can be used to perform business process modeling, two business process modeling notation that widely used are YAWL and BPMN. 
1) YAWL is both a workflow modeling language and an open-source workflow system [8]. The acronym YAWL stands for "Yet Another Workflow Language". Figure 1 shows the main notation of YAWL. YAWL notation consists of condition, task and decorator.

2) BPMN (Business Process Modelling Notation) has become one of the most widely used languages for the business process model. BPMN is supported by many tools (tools) and has been standardized by the Object Management Group (OMG). Figure 2 shows the main notation of BPMN. BPMN notation consists of event, task and gateway.

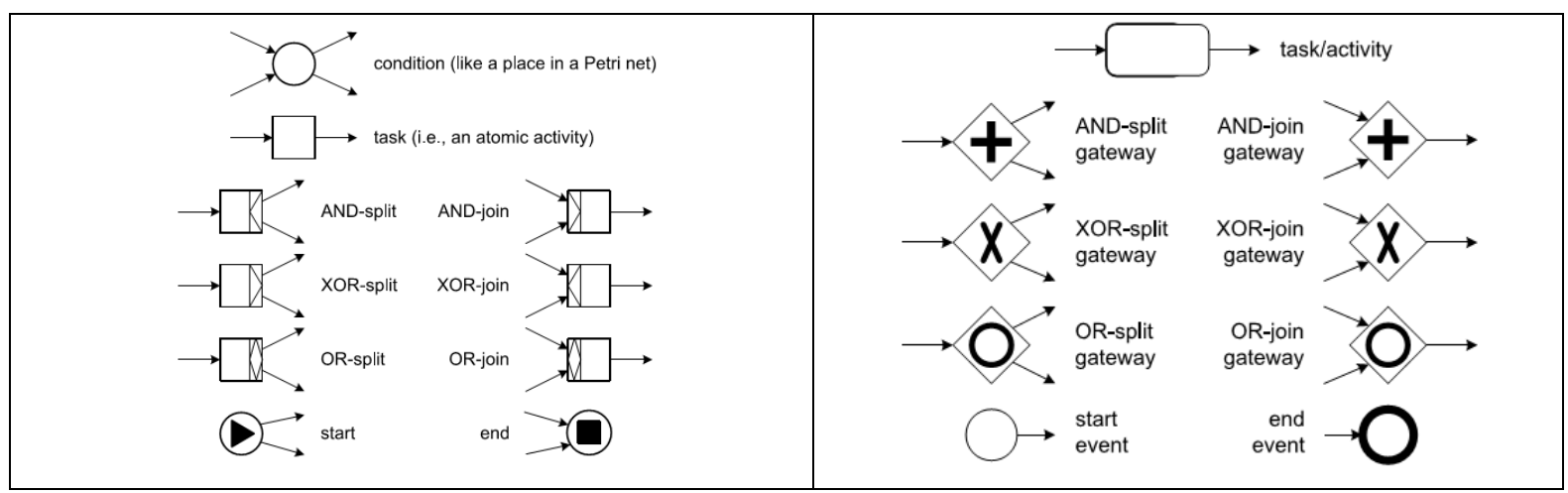

Figure 1. YAWL Notation

Figure 2. BPMN Notation

\section{Business Process Patterns}

Workflow Pattern Initiative classifies patterns of the business process into three main groups namely the control flow, data and resource (Hofstede, et al., 2010). These three groups have patterns as follows:

- Control flow

- Branching patterns: AND, OR, XOR split

○ Synchronization patterns: AND, OR, XOR join

- Iteration patterns: structured loop, arbitrary cycles, and recursion

- Multiple Instance (MI) patterns

- Concurrency patterns

- Cancellation patterns

- Trigger patterns

- Termination patterns: Implicit, and explicit termination

- Data

- Data visibility patterns

- Data interaction patterns

- Data transfer patterns

- Data-based routing patterns

\section{Related Research}

Research related to business process modeling has been carried out by (Terahadi \& Widagdo, 2014) and (Sunindyo, et al., 2014). Both of these studies do not support the execution of business processes automatically. The data model that found is not capable of storing rules to automatically select the route.

\section{Research Methodology}

This research uses the Waterfall Method which includes: 


\section{Requirements analysis and definition}

At this stage, the analysis conducted by researchers are:

1. Analysis of old system weaknesses

In the analysis of the weaknesses of the old system, the researcher uses analysis with the SWOT analysis.

2. Requirement analysis

The researcher analyzes the system requirements obtained from the analysis of system weaknesses.

\section{System and software design}

At this stage the researcher will implement the requirements in the form of blueprints. To assist in making the design of the system blueprint, the researcher uses Microsoft Visio 2016. The design stages include:

- Flowchart system.

- UML design (Use case diagram and Sequence diagram).

- Entity Relationship Diagram (ER Diagram).

- Interface Design

\section{Implementation and unit testing}

At this stage, software design is realized as a series of programs or program units. The testing involves verifying that each unit fills its specifications.

\section{Integration and system testing}

The individual units of the program are combined and tested as a complete system to verify whether it meets the software requirements or not. After the testing, the software can be delivered to the customer.

\section{Operation and maintenance}

Usually (although not always), this stage is the longest stage. The system is installed and used significantly. Maintenance involves correcting errors that are not found in the previous stages, increasing the implementation of the system unit, and improving system services as new requirements.

\section{Analysis and Design}

\section{Analysis}

Elements of process data: from the business process definition, found three main elements of business processes namely activities, the relationship between activities, and input/output. At the time of executing the business process, activities must be performed by a person or group of persons entitled to perform these activities.

Among the three main elements of the process data, the relationship between activities is the most important thing that must be addressed. The relationships between activities included in the control flow patterns. This is in accordance with the notation that defines the relationship between activities such as branching (split) and synchronizing (join). 
Relationship between activities: Among the three main elements of the process data, the relationship between activities is the most important thing that must be addressed. Types of relationships between activity can be determined by comparing the notation of YAWL in Figure 1 and BPMN in Figure 2. The beginning and end of the business process are expressed by the name of the start and end event. The relationship between activities described by the term split and join gateway consisting of three types namely AND, OR, and XOR.

By analyzing the business process modeling notation and patterns of business processes, it is known to the pattern that can be supported by this data model. The patters are described as follows.

- Control flow

1. Branching patterns

Branching or split patterns can be supported by the business process model because all the split patterns included in the data model.

2. Synchronization patterns

Synchronization or join pattern can be supported by the business process model because all the join patterns included in the data model

3. Iteration patterns

Iteration patterns are patterns that not have a special notation in YAWL or BPMN. However, the pattern can be formed by a combination of split and join. Iteration patterns can be supported by the business process model. Recursive iteration patterns cannot be supported because of the recursive calling from the activity itself before the activity completed.

4. Concurrency patterns

AND join is one of the concurrency patterns. The data model can support this pattern.

5. Termination patterns

Explicit termination patterns can be supported by the data model because every business process that modeled has a specific endpoint.

6. Multiple Instance (MI) patterns, Cancellation patterns, and Trigger patterns are not supported because it is not included in the process model.

- Data

Data-based routing pattern is supported by the model because of the process flow control rule can be stored into the data model.

Business process metadata: The terms that used in metadata are from BPMN such as an event, task and gateway. These three terms hereinafter referred to base process:

- Event, is a base process that placed in the beginning and the end of the business process.

- Task, is a base process that generates output.

- Gateway, is a base process that manages the control flow of the business process.

\section{Modeling of process business metadata}

Business process metadata described using Entity-Relationship Diagram (ERD) in Figure 3. There are nine entities namely, process, base process, data, role, event \& task, gateway, storage, process execution, and process execution step. Gateway entity has relationships with the base process entity to determine the type of logic gate that will be used on the gateway. A gateway can have a logic gate and pointed to several base processes.

\section{Overview of the Information System}

The type of information system is a transaction processing system. This system only supporting simple information processing and unable to interact with external systems. This information system is divided into two parts, namely the configuration and execution. 


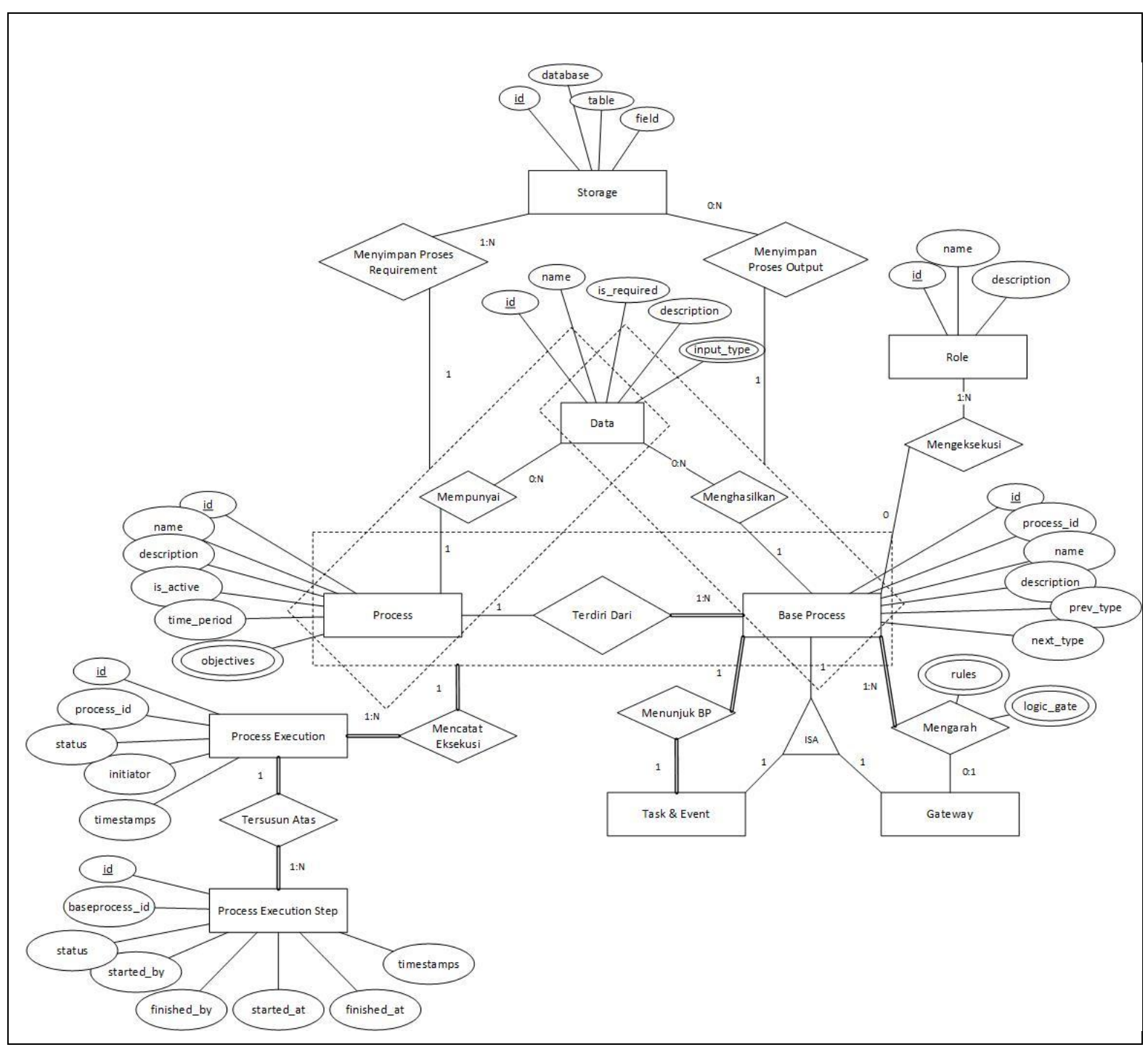

Figure 3. Entity Relationship Diagram (ERD) business process metadata

1) Business process configuration is the activity of defining business processes and their relationship to the metadata. The system administrator can perform business process configuration.

2) Business process execution is the activity of running a business process that has been defined. At the time of execution, the business process initiated by the roles that exist in the information system. Once initiated, the task of the business process executed by the respective role. The executor of business processes designed to control execution flow based on the relationship between the base process that has been defined. Figure 4 is a flowchart that illustrates the execution flow of business processes.

\section{Development and Testing}

\section{Design of Information System}

1) Functional requirements of information systems: divided into two functional needs namely, configuration and execution of the business process. Each functional requirement can be viewed in Table 1 and Table 2. 


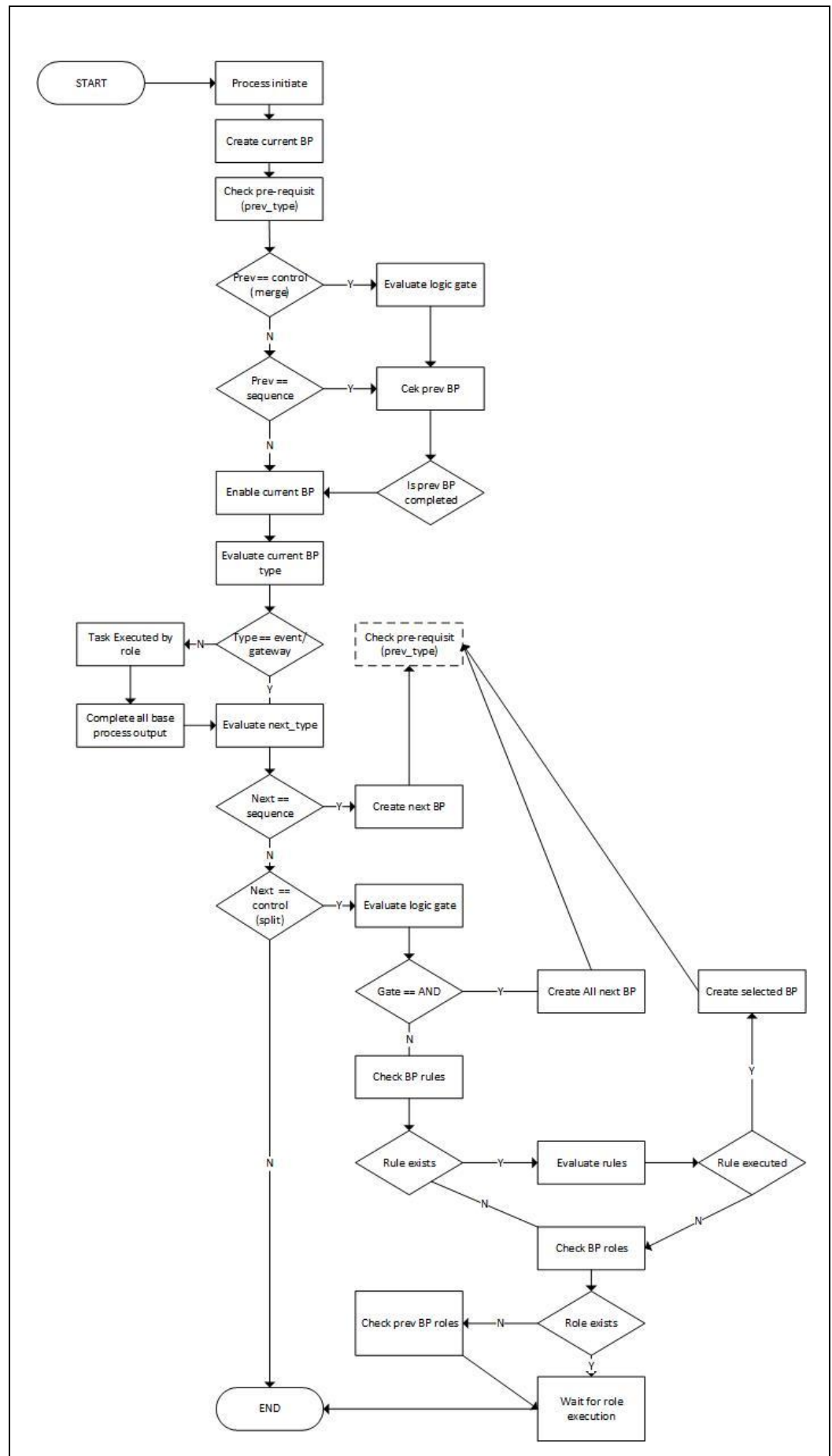

Figure 4. Process business execution

Table 1. Functional requirement for business process configuration

\begin{tabular}{|l|l|l|}
\hline No & SRS ID & Description \\
\hline 1 & SRS-CON-1 & An administrator can perform CRUD connection \\
\hline 2 & SRS-CON-2 & An administrator can perform CRUD role \\
\hline 3 & SRS-CON-3 & An administrator can perform CRUD user \\
\hline 4 & SRS-CON-4 & An administrator can perform CRUD business process \\
\hline
\end{tabular}


Table 2. Functional requirement for business process execution

\begin{tabular}{|l|l|l|}
\hline No & SRS ID & Description \\
\hline 1 & SRS-EXE-1 & User can start business processes \\
\hline 2 & SRS-EXE-2 & User can perform tasks according to the role owned \\
\hline 3 & SRS-EXE-3 & $\begin{array}{l}\text { The executor can control the flow of business process } \\
\text { execution }\end{array}$ \\
\hline 4 & SRS-EXE-4 & $\begin{array}{l}\text { The executor can move operational data into } \\
\text { operational data storage location that has been defined }\end{array}$ \\
\hline
\end{tabular}

2) Modeling of information system requirements: the entire functional requirements are modeled in the form of use cases that can be seen in Figure 5 and Figure 6.

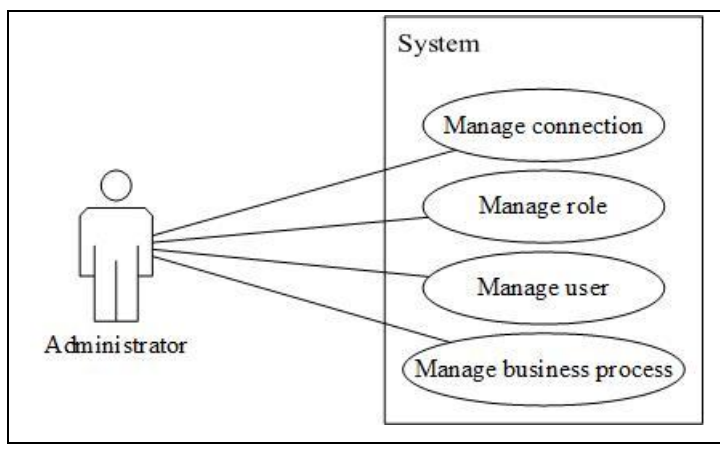

Figure 5. Use case for configuration of business process

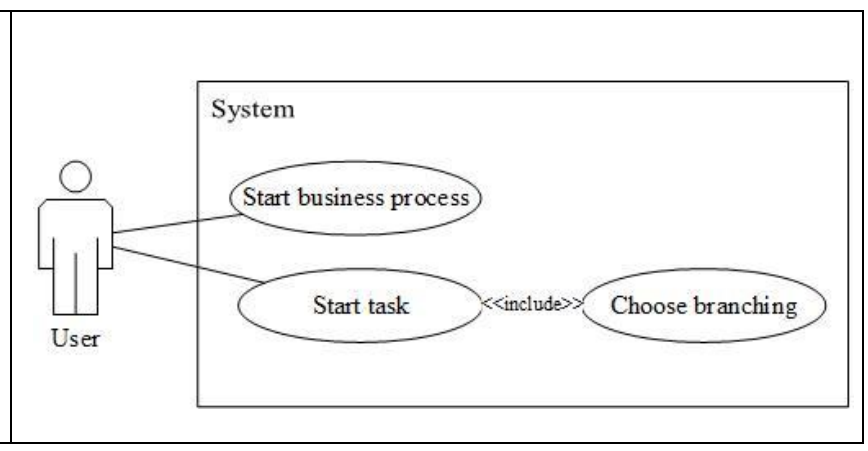

Figure 6. A use case diagram for execution of the business process

3) Class design: The design and implementation of information stem using an object-oriented approach. In object-oriented approach, the identification of classes is required to build the information system. The class diagram is shown in Figure 7.

\section{Implementation}

The ERD has been created is translated into relational tables which can be seen in Figure 8 and Figure 9. There are 22 tables formed by the ERD of business process metadata.

\section{Testing}

1) Objectives: tests performed had two objectives:

- Find out whether the information system can function properly in accordance with the functional requirement that has been set.

- Test whether patterns and the rules that have been defined in the business process successfully executed. 


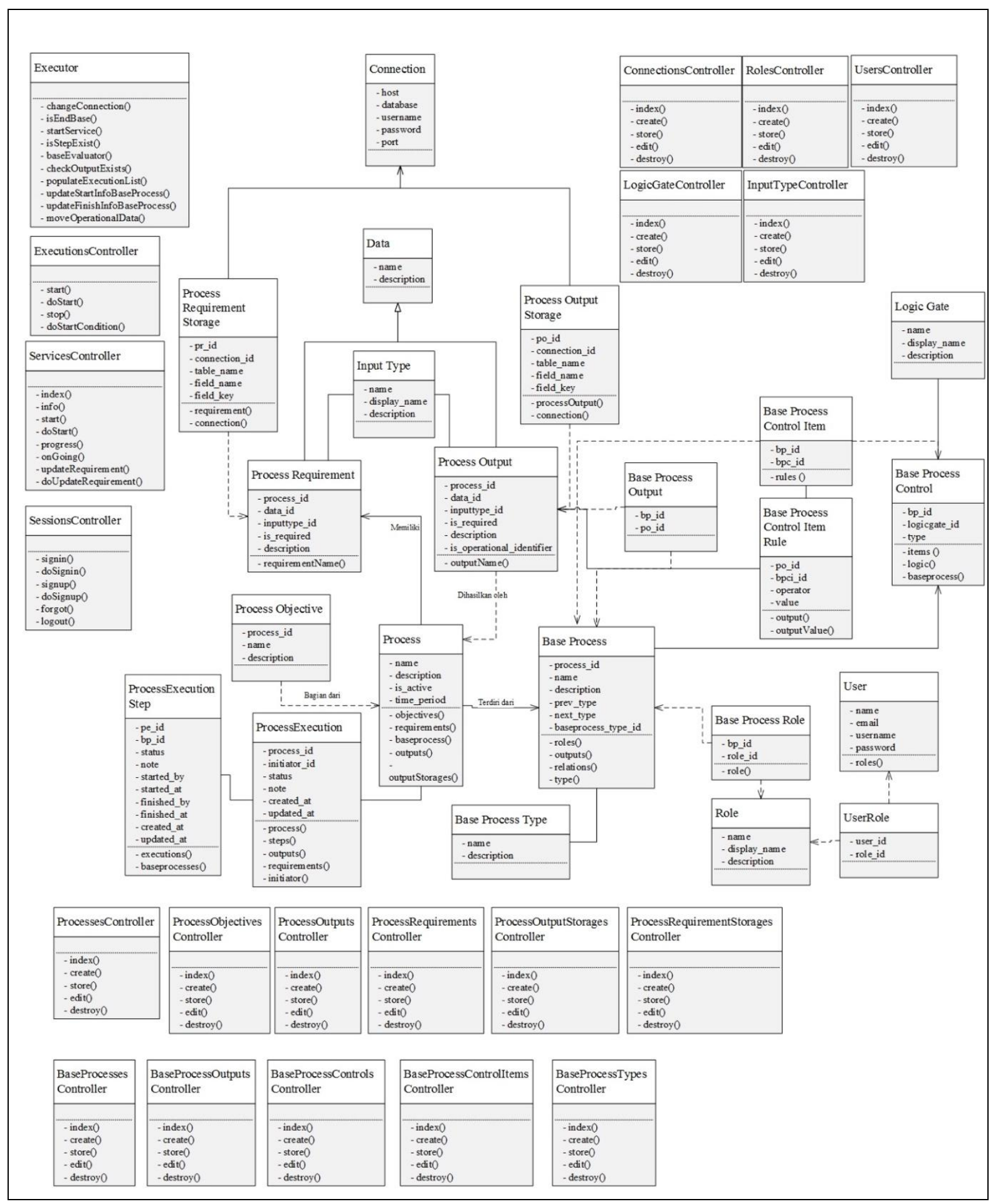

Figure 7. Process business execution 


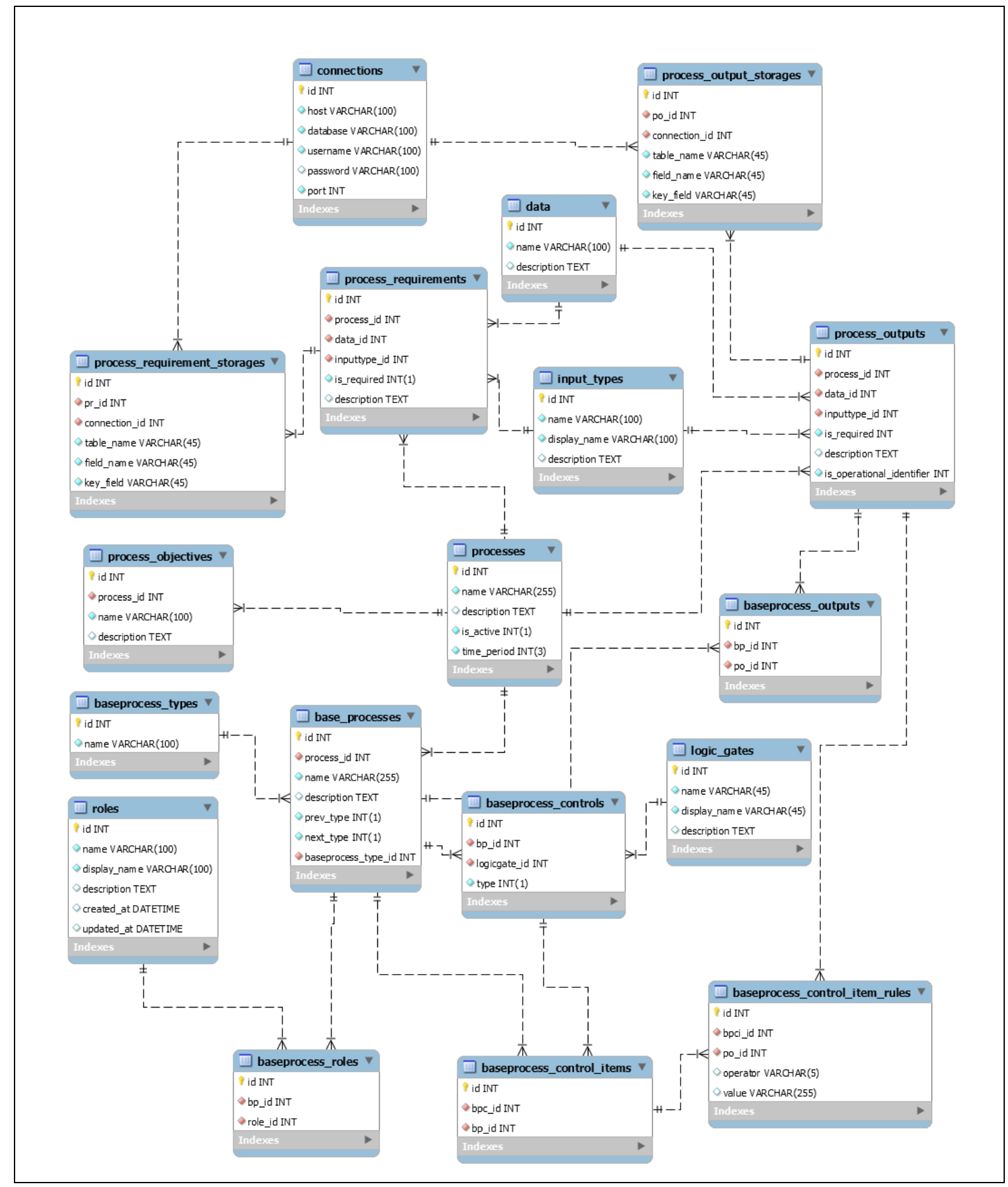

Figure 8. Relational table for configuration stage 


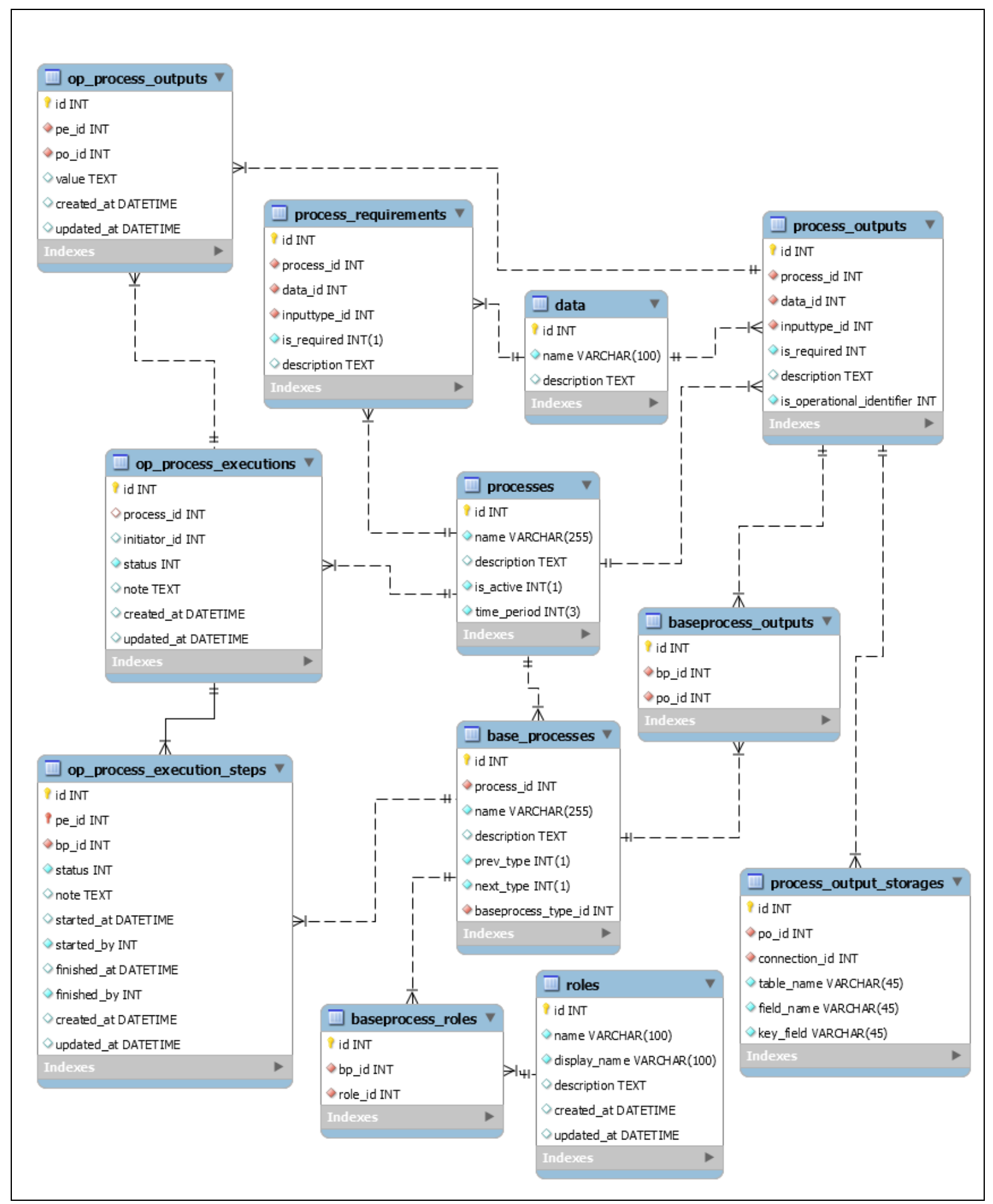

Figure 9. Relational table for execution stage

2) Testing scenario: testing is divided into two test, configuration, and execution test. The configuration test is done by defining business processes into information systems, this can be seen on Figure 10. The execution test is done by running the business processes that have been defined. The test case is a credit card submission process, this process has split, join, and recursive activity that can be seen on Figure 11. 


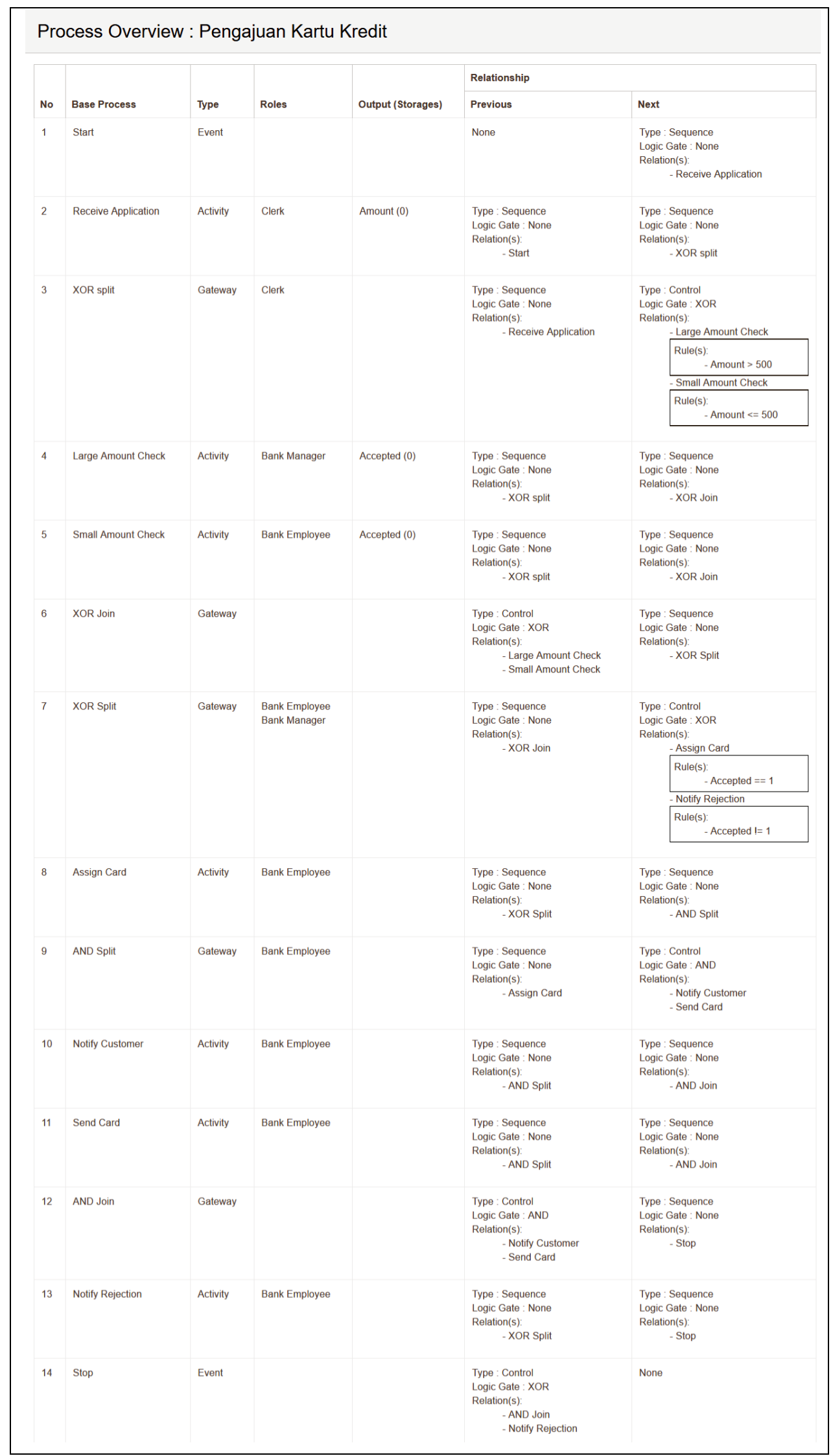

Figure 10. The configuration of credit card submission into the information system 


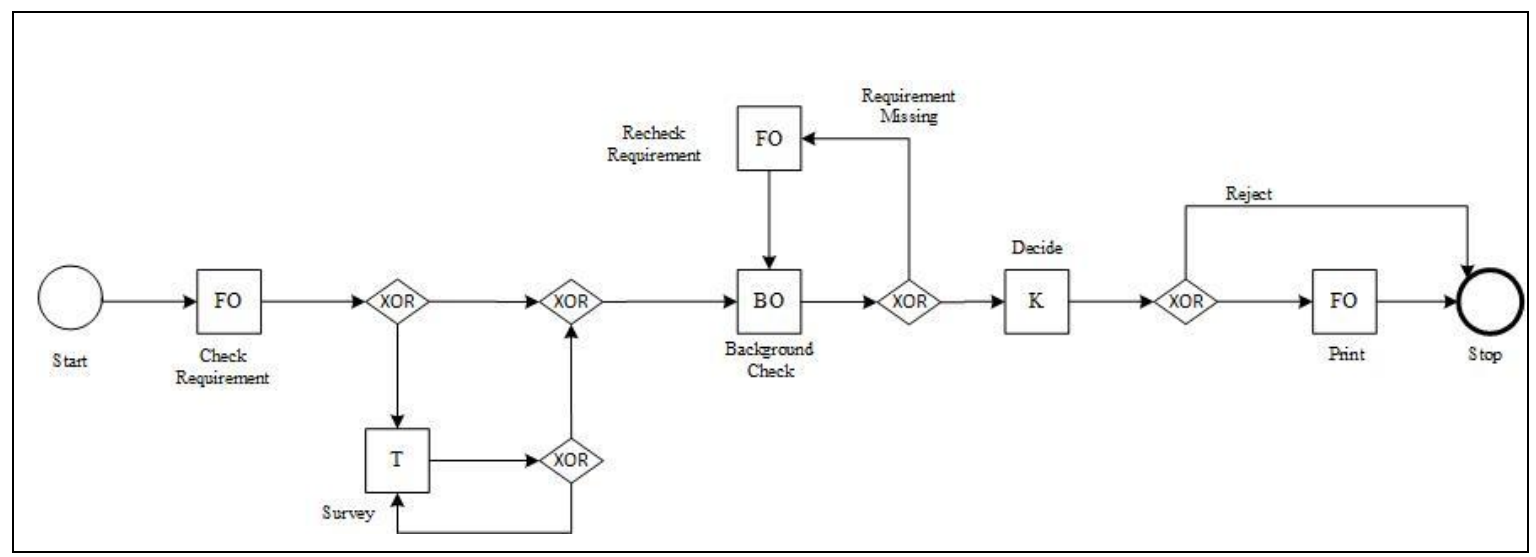

Figure 11. Flow for credit card submission

3) Testing result: based on test results of business process configuration can be seen in Figure 11 the entire functional requirement of configuration base process successfully implemented. The entire test case that have been defined successfully executed. Execution results can be seen in Table 3 .

Table 3. Evaluation of test case credit card submission

\begin{tabular}{|c|c|c|c|}
\hline Path & Base Process & Role & Data \\
\hline \multirow[t]{7}{*}{1} & Start & & \\
\hline & Receive Application & FO & Amount $=100$ \\
\hline & Small Amount Check & $\mathrm{BE}$ & Accepted $=1$ \\
\hline & Assign Card & $\mathrm{BE}$ & \\
\hline & Notify Customer & $\mathrm{BE}$ & \\
\hline & Send Card & $\mathrm{BE}$ & \\
\hline & Stop & & \\
\hline \multirow[t]{5}{*}{2} & Start & & \\
\hline & Receive Application & FO & Amount $=100$ \\
\hline & Small Amount Check & $\mathrm{BE}$ & Accepted $=0$ \\
\hline & Notify Rejection & $\mathrm{BE}$ & \\
\hline & Stop & & \\
\hline \multirow[t]{7}{*}{3} & Start & & \\
\hline & Receive Application & FO & Amount $=600$ \\
\hline & Large Amount Check & $\mathrm{BM}$ & Accepted $=1$ \\
\hline & Assign Card & $\mathrm{BE}$ & \\
\hline & Notify Customer & $\mathrm{BE}$ & \\
\hline & Send Card & $\mathrm{BE}$ & \\
\hline & Stop & & \\
\hline
\end{tabular}




\begin{tabular}{|l|l|l|l|}
\hline 4 & Start & & \\
\hline & Receive Application & FO & Amount $=600$ \\
\hline & Large Amount Check & BM & Accepted =0 \\
\hline & Notify Rejection & BE & \\
\hline & Stop & & \\
\hline
\end{tabular}

4) Analysis of the test result: The data model is able to store business processes and the relationship between activities in business process. Executor successfully execute the business process patterns that exist in business process. Executor successfully perform flow control process based on the rule that has been defined. After the execution of business process, the data generated during the execution were successfully stored into the operational database.

\section{Conclusion}

Based on all the stages that have been implemented in the research, some conclusions can be drawn as follows:

1. Business process metadata developed by analyzing patterns that exist in business processes can store relationships between activities in a database structure. This enables the automation of the execution of relations between activities by adding rule relations between activities. The transaction processing system can be used to define and execute business processes that have been defined.

2. The information system that was built has been successfully used to configure business processes. Business process compilers such as activities, process requirements, data generated by activities, data storage locations, relationships between activities, and rule relations between activities can be stored into business process metadata.

3. The information system that was built has succeeded in executing a business process that has been configured, either manually or automatically, based on the rule of relations between activities that have been defined. After the business process has been executed, the data that has been generated in the activity is stored in an operational database that has been defined at the configuration stage.

4. With this information system, the organization does not need to develop information systems from the beginning to save transactional and administrative data from a business process.

5. This information system only can check 1 rule at one time, for example, user age greater than 30 years.

6. This information system can be improved to handle more than one rule, for example, user age greater than 30 years and less than 40 years.

\section{References}

Aalst, W. v. d., Hofstede, A. t., Kiepuszewski, B. \& Baros, A., 2003. Workflow Patterns. Ditributed and Parallel Databases 14, pp. 5-51.

Al-Mamary, Y. H. S., Shamsuddin, A. \& Aziati, N., 2014. The Role of Different Types of Information Systems In Business Organizations : A Review. International Journal of Research (IJR), Volume-1, Issue-7, August 2014 ISSN 2348-6848, pp. 1279-1285.

Becker, J., Rosemann, M. \& Uthmann, C. v., 2000. Guidelines of Business Process Modelling. In: Business Process Managemen, LNCS 1806. Berlin: Springer, pp. 30-49. 
Davenport, T. H. \& Short, J. E., 1990. The new industrial engineering: information technology and business process redesign., s.l.: s.n.

Ghaebi, 2016. University of Arak. [Online]

Available at: http://araku.ac.ir/ a fiantial/ISR_Lec_[4].pdf

Glykas, M., 2013. Business Process Management : Theory and Applications. s.1.:Springer.

Hammer, M. \& Champy, J., 2009. Reengineering the Corporation. s.1.:Collins Business Essentials.

Hofstede, A. H. M. t., van der Aalst, W. M., Adams, M. \& Russell, N., 2010. Modern Business Process Automation. Berlin: Springer.

NISO, 2004. Understanding Metadata. National Information Standards.

OMG, t.thn. BPMN 2.0.2. [Online]

Available at: http://www.omg.org/spec/BPMN/2.0.2/PDF/ [Accessed 23 March 2016].

Terahadi, F. \& Widagdo, T. E., 2014. Model Pengembangan Aplikasi Pendukung Layanan Dengan Memanfaatkan Metadata Proses. Bandung, Program Studi Teknik Informatika, ITB.

Porter, M. E. \& Millar, V. E., 1985. How information gives you competitive advantage.. In: Boston: Harvard Business Review.

Srinivas, N. \& DBA, S. A.-D., 2012. Management Information Systems and Its Support to Sustainable Small and Medium Enterprises. International Journal of Business and Management; Vol. 7, No. 19, pp. 125-131.

Sunindyo, W., Hendrajaya, B., Saptawati, G. P. \& Widagdo, T. E., 2014. Document Tracking Technology to Support Indonesia Local E-Goverments, Bandung: Data and Sorfware Engineering Research Group of Electrical Enginnering and Informatics, Bandung Institute of Technology.

Workflow Patterns Initiative, 2011. Workflow Patterns Home Page. [Online] Available at: http://www.workflowpatterns.com/ [Accessed 1 May 2016].

Workflow Patterns Initiative, 2011. Workflow Patterns | Patterns | Control. [Online] Available at: http://www.workflowpatterns.com/patterns/control/ [Accessed 1 May 2016]. 